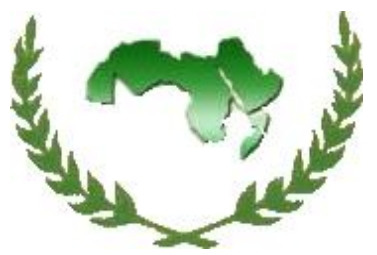

Arab Univ.

J. Agric. Sci.,

Ain Shams Univ.,

Cairo, 15(1), 89-100, 2007

\title{
DEVELOPMENT OF VOLATILE COMPOUNDS OF AVOCADO AND CASIMIROA DURING FRUIT MATURATION
}

\author{
Magda A. Abd El-Mageed ${ }^{1}$ \\ 1- Department of Flavour and Aromatic Chemistry, National Research Centre, Dokki, Cairo, \\ Egypt
}

[8]

Keywords: Avocado Fruits, Casimiroa Fruits, Volatile Components, Maturation

\begin{abstract}
Avocado fruits (Persea americana Mill) cv. Fuerte and white sapote (Casimiroa edulis) cv. Rotaceae cultivated in Egypt were collected at different maturity stages:green mature,commercial ripe and over ripe stages. The headspace volatiles of each maturity stage was isolated and subjected to gas chromatography- mass spectrometric analysis. A total of 43 components were identified in avocado aroma including; terpenes (15), esters (8), aldehydes (8), alcohols (6), ketones (2), thiazoles (1), pyridines (1), toluene and acetic acid, where as 18 compounds were, identified in casimiroa aroma, they contained (4) esters, (6) alcohols, (4) aldehydes, (3) terpenes and (1) ketone. Ethanol $(\mathrm{Z})-3$ - hexenol and $(E)$-2- hexenal were the major constituents in green and ripe fruits of avocado whereas they decreased at the final stage of maturation. Over ripe avocado fruits had the highest content of esters (ethyl ethanoate, ethyl acetate and methyl propanoate) and terpenoides especially d-limonene and z-nerolidol. Esters and alcohols comprised more than $85 \%$ of the total concentration of volatiles in casimiroa fruits during three stages of maturation. The highest content of ethyl butanoate (sweet and fruity aroma) and ethanol revealed the most prominent effect on consumer acceptability of the cosimiroa flavour attributes. It is obvious that maturation of the fruits was associated with remarkable changes in the volatiles that mainly affect their flavour.
\end{abstract}

\section{INTRODUCTION}

The avocado pear (Persea americana Mill.) is cultivated in nearly all tropical and subtropical countries. The soft oily flesh of the fruit is eaten uncooked as part of a salad or served as an appetizer. The fruit shows great variability in size, shape, weight and chemical composition, depending on the variety, the climatic conditions and the agricultural practices followed during their growth. According to their characteristics the varieties are classified in three types: Mexican, Guatemalan and West Indian (Herrmann, 1994).

From a nutritional point of view, avocado is an important and high caloric fruit. Indeed its high content of unsaturated fatty acids is one of its distinguishing characteristics. Moreover, avocado is rich in vitamin $\mathrm{E}$, ascorbic acid, vitamin $\mathrm{B}_{6}, \beta$ carotene, and potassium (Bergh, 1992; Gains, 1992). Unlike many other fruits, the ripening or softening of avocado does not occur during maturity on the tree, but takes place several days after the fruit has been picked. It seems that there is a flow of inhibitive components from the leaves to the fruit, preventing fruit from softening on the tree (Werman and Neeman, 1987). Avocado is also one of the most rapidly ripening fruits, often completing ripening within 5-7 days following harvest (Seymour and Tucker 1993) Fruit maturity and picking time are determined according to external markers (colour and size), or by measuring oil content in the flesh (Werman and Neeman, 1987). However, Martinez and Moreno (1995) reported that determining the commercial maturity of the avocado is difficult because the start of ripening is not accompanied by visible external changes. The minimum oil content neces- 
sary for marketing avocado fruit is $8 \%$, after full maturation, values greater than $20 \%$ can occur associated with changes in oil composition. Concentrations of unsaturated fatty acids increase and those of saturated fatty acids decrease (Martinez and Moreno, 1995).

The avocado has been for thousands of years, and still is, a popular food in Central America. It is a nutritious fruit but the sugar content is low; therefore, it can be recommended as a high energy food for the diabetic (Samson, 1986; Swisher, 1988). The high oil content of the fruit has attracted special attention with respect to its composition (Torres et al 1987 and Ozdemir and Topuz, 2004) but relatively little work has been done on the composition of the volatile components of avocado fruit (Yamaguchi et al 1983; Pino et al 2000 and Pino, 2004).

Casimiroa edulis Llave et Lex. (Rutaceae) is a tree that is widely distributed throughout Mexico and Central America. The edible fruits, commonly known as "zapote blanco", have a pleasant flavour and are consumed as a tropical dessert fruit. The Pharmacopeia of Mexico once recognized both the fruit and seed of $C$. edulis, with the former used as an anthelmintic and the latter as a vulnerary (Power and Callan, 1911). Ito et al (1998) extracted constituents derived from seeds, fruits and leaves of Casimiroa edulis, having antimutagenic and anticancer effects.

Yonemoto et al (2006) reported that changes in fruit and seed size, peel colour, seed colour, TSS, sugars and polyphenols contents were determined in white sapote (Casimiroa edulis cv.Cuccio) pollinated at different times to develop a practical index to determine harvesting time during fruit development. Fruit growth was sigmoidal and, therefore, not suitable for use as an index of maturity. Accumulated temp. (AT), the sum of hourly temperature or days after pollination (DAP) could be used as an index. An AT of Approx. 120 x 103 degrees $\mathrm{C}$ h or 212 DAP were required for maturity. There was a strong correlation between TSS content and percentage dry matter (DM) in pulp; a \% DM= 18.0 could be used as an index of fruit maturity.

Postharvest behaviour of Casimiroa edulis have been investigated with many authors (Walker et al 1990; McCain, 1993; Nerd et al 1994). Fruit ripening as affected by storage temperature in white sapote (Casimiroa edulis) was studed by Yonemoto et al 2000 and 2002. Also its pharmacology effects were investigated by (Magos $\boldsymbol{e t}$ al 1995 and Caccres et al 1993, but there was very little work have been done on flavour of Casimiroa (Everett, 1947; Mizrahi et al 1991) further more there were no litelature contains the volatile components of casimiroa.

The aim of this study was to follow the changes in volatile components of avocado and casimiroa during fruit growth and ripening.

\section{MATERIALS AND METHODS}

The fresh green mature avocado (Persea Americana Mill) cv.Fuerte and white sapote (Casimiroa edulis) cv. Rotaceae were obtained from an orchard located at Cairo- Alexandria desert road, and immediately stored at $5^{\circ} \mathrm{c}$ until analysis. Concerning avocado fruits harvest date was at first of November, fifty days later, mature fruits were used as ripe samples. After 2 weeks later, stored mature fruits were sampled as over ripe stage. Harvest date of casimiroa was at first of October, seven days later mature fruits stored at $5^{\circ} \mathrm{C}$ were used as ripe samples, after nine days, stored mature fruits were sampled as over ripe stage. Mature green fruits were characterized by firmness, large in size, peer in shape, green in colour with no characteristric flavour, while commercial ripe fruits were softer in texture and more developed in colour. The over ripe fruits were very soft with brown coloured spots on skin and its low firmness does not allow any commercial use of the fruits. The authentic compounds were purchased from Sigma and Aldrich Co., s.

\section{Isolation of headspace volatiles}

The volatiles in the headspace of each sample under investigation were isolated by using a dynamic headspace system. The samples were purged for $1 \mathrm{~h}$ with nitrogen gas (grade of $\mathrm{N} 2>$ $99.99 \%$ ) at a flow rate $100 \mathrm{ml} / \mathrm{min}$. The headspace volatiles were swept into cold traps containing diethyl ether and pentane $(1: 1, \mathrm{v} / \mathrm{v})$ and held at -10 ${ }^{\circ} \mathrm{C}$. The solvents containing the volatiles were dried over anhydrous sodium sulfate for $1 \mathrm{~h}$. The volatiles were obtained by evaporation of the solvents under reduced pressure (Fadel et al 2000).

\section{Gas chromatographic (GC) analysis}

GC analysis was performed by using HewlettPackard model 5890 equipped with a flame ionization detector (FID). A fused silica capillary column DB5 (60m x $0.32 \mathrm{~mm}$ id) was used. The oven temperature was maintained initially at $50^{\circ} \mathrm{C}$ for 5 
min, then programmed from 50 to $250^{\circ} \mathrm{C}$ at a rate of $4^{\circ} \mathrm{C} / \mathrm{min}$. Helium was used as the carrier gas, at flow rate $1.1 \mathrm{ml} / \mathrm{min}$. The injector and detector temperatures were 220 and $250^{\circ} \mathrm{C}$, respectively. The retention indices (Kovats index) of the separated volatile components were calculated using hydrocarbon (C8-C22, Aldrich CO.) as references.

\section{Gas chromatographic-mass spectrometric (GC- MS) analysis}

The analysis was carried out by using a coupled gas chromatography Hewlett-Packard (5890)/mass spectrometry Hewlett-Packard-MS (5970). The ionization voltage was $70 \mathrm{eV}$, mass range $\mathrm{m} / \mathrm{z}$ 39-400amu. The GC condition was carried out as mentioned above. The isolated peaks were identified by matching with data from the library of mass spectra (NIST) and compared with those of authentic compounds and published data (Adams, 1995). The quantitative determination was carried out based on peak area integration.

\section{RESULTS AND DISCUSSION}

Volatile components in headspace of three ripening stages of Avocado and Casimiroa fruits

\section{Avocado (Persea Americana Mill) cv. Fuerte}

The separated volatile components as identified by comparison of their mass spectra with library (NIST) and with those of authentic compound and published data and with their retention indices on DB5 column are cited together with their area percentages in Table (1).

A typical gas chromatograms of the volatiles of green, ripe and over ripe samples of avocado fruit are shown in Fig. (1). The total area percentages of the main chemical classes of volatile components in the headspace of avocado ripening through three stages are shown in Fig. (2).

Forty three volatile components were identified and reported in Table (1), they include; terpenes (15), esters (8), aldehydes (8), alcohols (6), ketones (2), thiazoles (1), pyridines (1), toluene and acetic acid. Although terpenic hydrocarbons appear predominant in number (15 terpenes), they comprised $9.7 \%$ of the total volatiles in green avocado, $15.71 \%$ in ripe and $26.65 \%$ in over ripe sample, Fig. (2). This gradual increase in concentration through three stages of maturation was attributed to the gradual increase in the major terpenes d-limonene, $z$-nerolidol, $\alpha$-farnesene and caryophellene oxide, Table (1). Pino (2004) found that $\mathrm{z}$-nerolidol, $\alpha$-farnesene, ( $\beta$-caryophyllene, caryophyllene oxide and $\alpha$-copaene were the predominant class of volatiles constituents of steam distillated avocado fruits. Esters were the predominant class of constituents in volatiles of avocado during three stages of ripening, their total yield were $32.38 \%, 29.39 \%$ and $34.02 \%$ in green, ripe and over ripe stages, respectively, Fig. (2). The major esters were ethyl ethanoate, ethyl acetate in the three stages of maturation besides ethyl hexanoate in green and rip and methyl propanoate in ripe and over ripe samples, Table (1). Takeoka $\boldsymbol{e t}$ al (1988) concluded that esters were the main constituents of the over ripe stage of maturation and giving the fruits a more fruity aroma. However these fruits had no characteristic flavour.

Six alcohols were identified in volatiles of avocado fruits, ethanol was the most abundant volatile in green avocado (30.84\%), it decreased gradually during ripening and over ripe stage (23.34 and 21.77, respectively) Table (1). Z-3-Hexenol the second major alcohol in green avocado $(1.51 \%)$ showed remarkable increase in ripe stage $(9,13 \%)$ followed by sharp decrease at final stage of maturation $(0.18 \%)$, Table (1). Visai and Vanoli (1997) reported that Z-3-hexenol have a typical green leaf aroma. Also the dominating green note of avocado fruit is attributed to certain aldehydes, particularly (E)-2- hexenal which was the major aldehyde in green stage $(15.38 \%)$ and decreased in the ripe and over ripe stages of maturation $(13.66 \%$, and $11.32 \%$ respectively) Table (1).

As shown in Fig. (2) maturation revealed a gradual decrease in the total aldehyde contents of ripe and over ripe avocado. Abd El-Mageed (2001) found that $\mathrm{C}_{6}$-aldehydes and alcohols are the major compounds isolated from green immature peach fruits and they decreased during the final stage of fruit maturation. Unsaturated $\mathrm{C}_{6}$ aldehydes and alcohols such as hexanal and hexenol are products of lipid degradation. Destroying the cell material, the lipolytic enzyme leak from the cell compartments and split the alkyl lipids. The released fatty acids are then decomposed into aroma compounds (Pfannhauser, 1988).

\section{White Sapote (Casimiroa edulis) cv. Rotaceae}

The separated volatile components as identified by comparison of their mass spectra with library (NIST) and with those of authentic compound and published data and with their retention indices on DB5 column are cited together with their area percentages in Table (2).

Arab Univ. J. Agric. Sci., 15(1), 2007 
Arab Univ. J. Agric. Sci., 15(1), 2007 


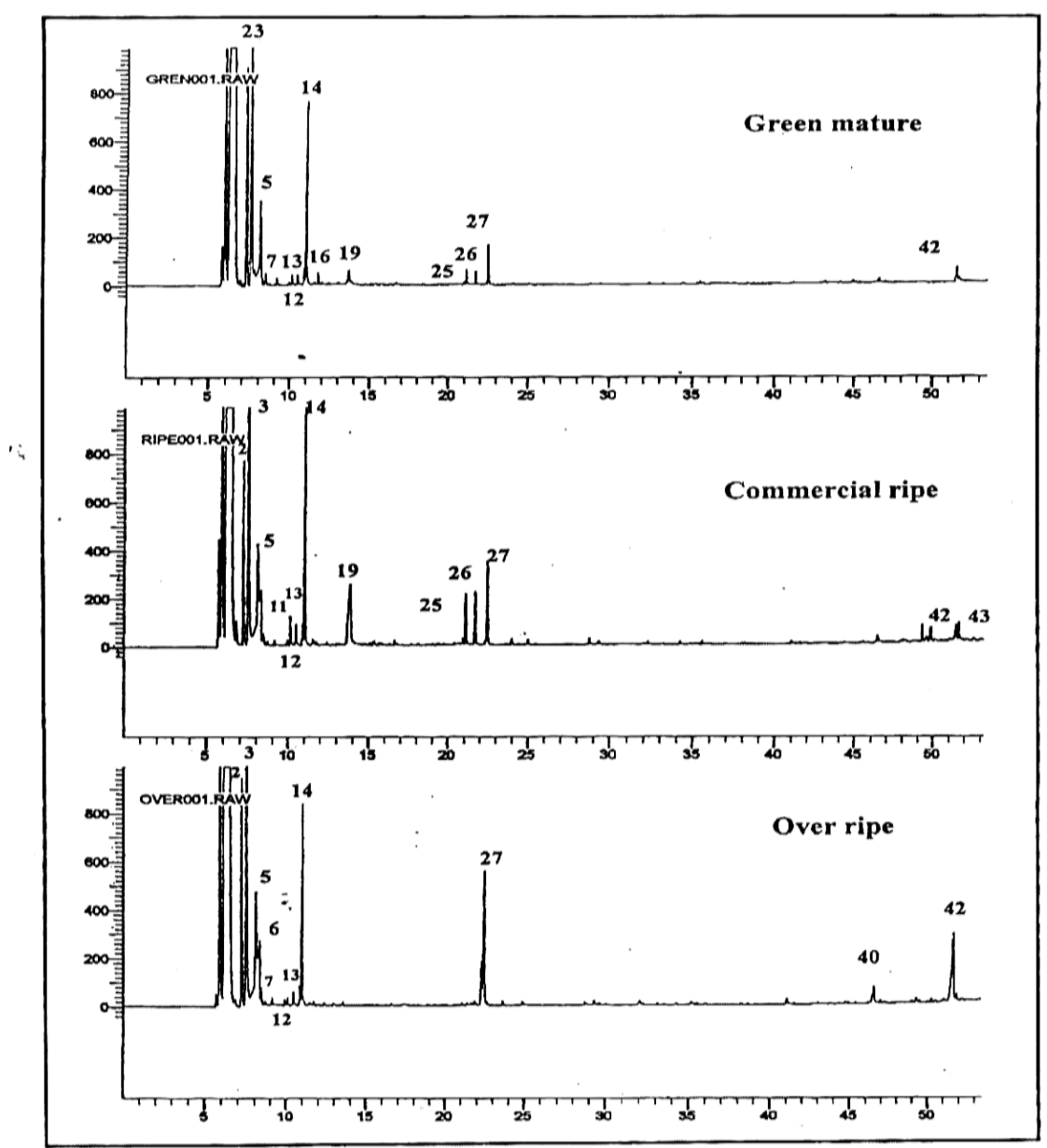

Fig. 1. Gas chromatograph of the volatiles in headspace of avocado during maturation (green mature, ripe and over ripe)

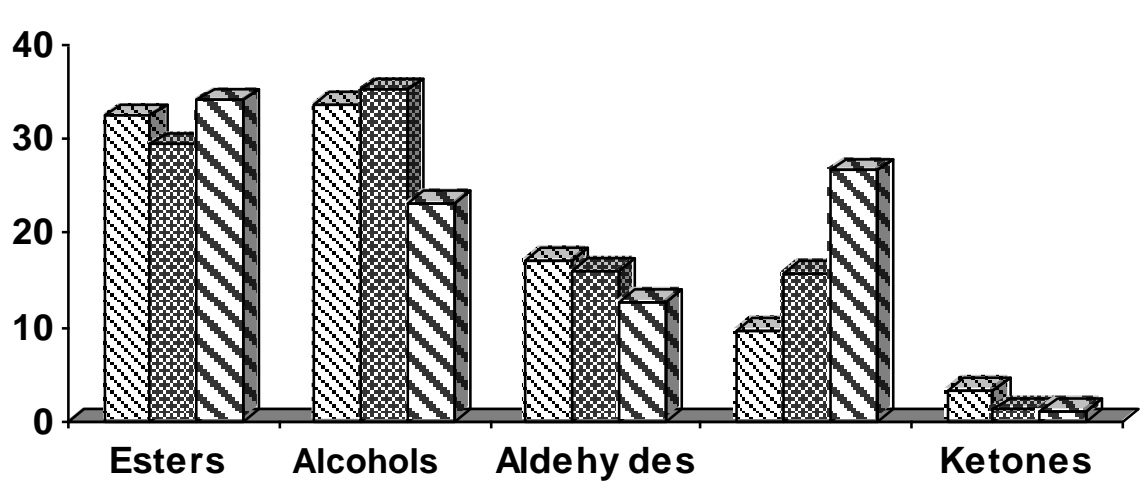

$\otimes$ Green mature $⿴$ Commercial ripe $\Delta$ Over ripe

Fig. 2. The total area percentages of the main chemical classes of volatile components in the headspace of avocado maturation 
Arab Univ. J. Agric. Sci., 15(1), 2007 
A typical gas chromatograms of the volatiles of green, ripe and over ripe samples of casimiroa fruit are shown in Fig. (3). The total area percentages of the main chemical classes of volatile components in the headspace of casimiroa ripening through three stages are shown in Fig. (4).

Eighteen compounds were identified and reported in Table (2), they contained; 4 esters, 6 alcohols, 4 aldehydes 3 terpenes and 1 ketone.

Esters were the predominant class of constituents in volaties of casimiroa during three stages of maturation, they comprised $83.1 \%, 73.14 \%$ and $55.49 \%$ of the total volatiles in green, ripe and over ripe stages, respectively Fig. (4). The major ester compound was ethylbutyrate, it represented by $75.16 \%, 61.55 \%$ and $33.01 \%$ in green, ripe and over ripe stages of maturation, respectively Table (2).

Alcohols were the second major compounds in headspace volatiles of casimiroa Table (2). On the contrary to the avocado maturation the total alcohol contents showed remarkable increase $(10.06 \%$
$12.8 \%$ and $30.88 \%$ ) in green, ripe and over ripe stages respectively, Fig. (4), the high increase in total alcohol content in over ripe sample was attributed to the great increase in ethanol $(21.74 \%$, the major alcohol in all samples), 1-penten-3- ol (1.75\%), 3-methyl butanol (3.84\%) and octanol (2.55\%) Table (2).

Aldehydes and terpenoides showed the same trend through the three stages of maturation Fig. (4). From the aforementioned results, it can be concluded that ethanol, ethyl ethanoate, ethyl acetate, E-2-hexenal, Z-3-hexenol, limonene and Znerolidol were the major volatiles in avocado fruit and play an important role in avocado maturation.

The presence of ethylbutyrate and ethanol as predominant volatile compounds may be responsible for consumer acceptability of casimiroa fruit flavour attribute. It is obvious that maturation of the fruits was associated with remarkable changes in the volatiles that mainly affect their over all flavour.

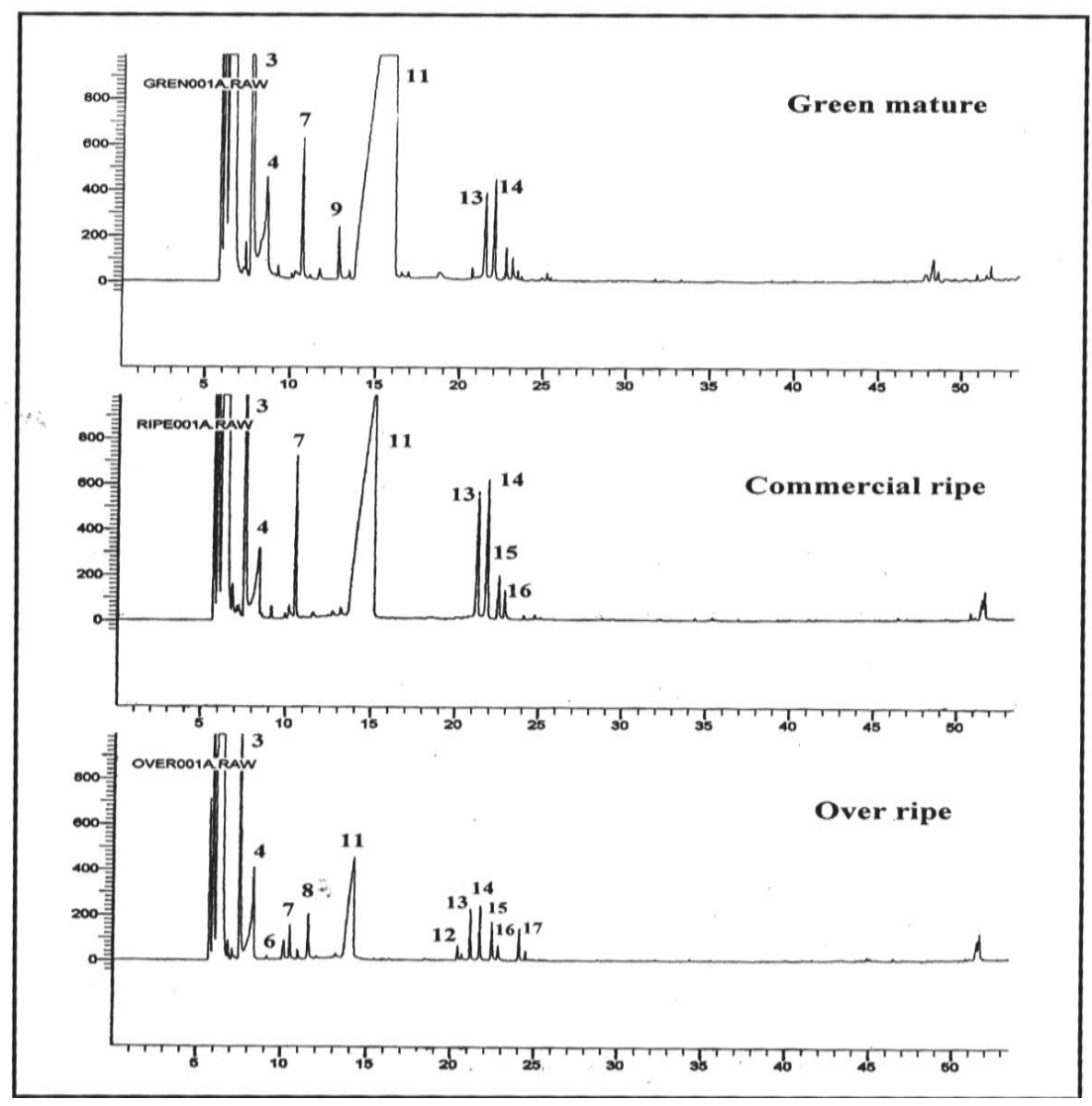

Fig. 3. Gas chromatograph of the volatiles in headspace of casimiroa during maturation (green, ripe and over ripe) 


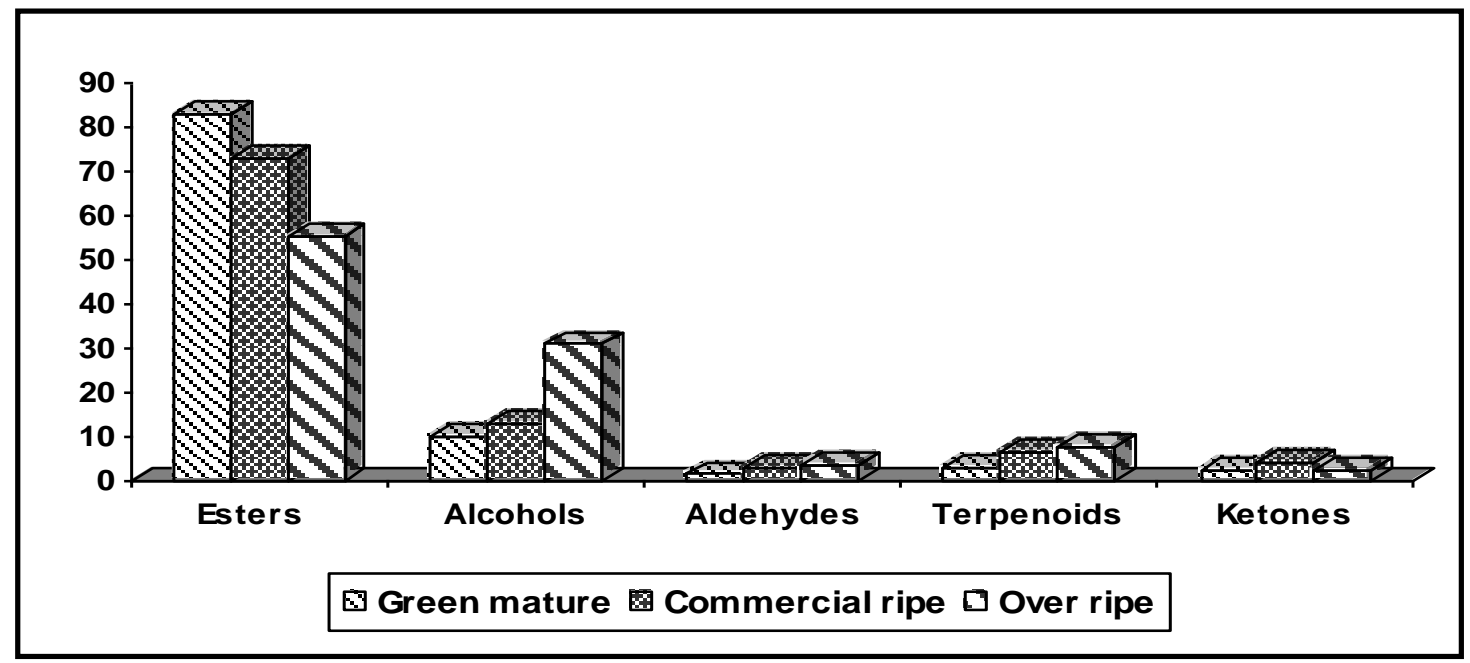

Fig. 4. The total area percentages of the main chemical classes of volatile components in the headspace of casimiroa maturation

\section{REFERENCES}

Adams, R.P. (1995). Identification of Essential Oil Components by Gas Chromatography/mass Spectrometry. Allured Publishing Carol Stream. Ilinois, USA.

Abd EL-Mageed, M.A. (2001). Development of volatile compounds of Peach and Apricot during fruit maturation. Egyptian J. of Nutrition 16(2): 1-27.

Bergh, B. (1992). Nutritious Value of Avocado (pp. 123-135). CA: California Avocado Society Book.

Caceres, A.; L. Figueroa; A.M. Taracena and B. Samayoa (1993). Plants used in Guatemala for the treatment of respiratory diseases. 2. Evaluation of activity of 16 plants against Gram-positive bacteria. J. of Ethnopharmacology. 39(1): 77-82.

Everett, P. (1947). The white sapote, Alittle Known sub-tropical fruit which can be grown in citrus districts. N.Z.J. Agric. 74: 470.

Fadel, H.M.; M.A. Abd El-Mageed; M.M. Mostafa and N.F. El-Sharouny (2000). Quality and flavour stability of freeze dried banana and apple fruits- Egyptian J. of Nutrition, 15(1): 1-25.

Gains, A. (1992). Avocados will lower your cholesterol. Here's Health (April), 36-37.

Herrmann, K. (1994). Uber die inhaltsstoffe und die verwendung wichtiger exotischer Obstarten. III. Acocado un Litschi. Ind. Obst Gemuseverwertung, 79: 41-46.
Ito, A.; L.A. Shamon; B. Yu; E.M. Greenwood; S.K. Lee; R.B. van Breemen; R.G. Mehta; N.R. Farnsworth; H.S. Fong; J.M. Pezzuto and D. Kinghorn (1998). Antimutagenic constituents of Casimiroa edulis with potential cancer chemopreventive activity. J. Agric. Food Chem. 46: 35093516.

Magos, G.A.; H. Vidrio and R.Enriquez (1995). Pharmacology of Casimiroa edulis; III. Relaxant and contractile effects in rat aortic rings. J. of Ethnopharmacology 47(1): 1-8.

Martinez, N.L. and R.V. Moreno (1995). Parameters for determining the maturity of avocados. Industries-Alimentaires et Agricoles. 112 (4): 200-203.

McCain, R. (1993). Goldenberry, passion fruit and white sapote: potential fruits for cool subtropical areas. Proceedings of the Second National Symposium: New crops, exploration, research and commercialization, Indianapolis, Indiana, October 6-9, 1991. John wiley and Sons, Inc., New York, USA: 1993. pp. 479-486.

Mizrahi, Y.; H. Cohen and D. Gur (1991). Introduction and development of new subtropical fruits. Israel J. of Botany. 40(3): 261-262.

Nerd, A.; J.A. Aronson and Y. Mizrahi (1994). Introduction and dome- stication of rare and wild fruit and nut trees for desert areas. WANATCA Yearbook. 18: 42-53.

Ozdemir, F. and A. Topuz (2004). changes in dry matter, oil content and fatty acid composition of avocado during harvesting time and post- 
harvesting ripening period. Food Chem. 86(1): 79-83.

Pfannhauser, W. (1988). Sensorische und instrumentelle analytische untersuchungen des kiwiaromas. Z. Lebensm. Unters Forsch 187: 224228.

Pino, J.A. (2004). Volatile components of Avocado (Persea americana Mill) cv. Moro grown in Cuba. J. Essent. Oil Res., 16: 139-140.

Pino J.; A. Rosado and J. Aguero (2000). Volatille components of Avocado (Persea americana Mill.) Fruits. J. Essent. Oil Res., 12: 377378.

Power, F.B. and T. Callan (1911). The constituents of the seeds of Casimiroa edulis. J. Chem. Soc., 1993-2012.

Samson, J.A. (1986). Tropical Fruits, $2^{\text {nd }}$ Edition. p. 235. Longman, London.

Seymour, G.B. and G.A. Tuker (1993). Avocado. In: G.B. Seymour, J. Tayler, and G.A. Tucker (eds), Biochemistry of Fruit Ripening (pp. 5381) Chapman and Hall, London.

Swisher, E.H. (1988). Avocado oil from food use to skin care. Journal of American Oil Chemists Association 65: 1704-1706.

Takeoka, G.R.M.; R.A. Flath; M. Gunter and W. Jennings (1988). Nectarine volatiles: vacuum steam distillation vs, headspace sampling. J. Agric. Food Chem. 36: 553-560.

Torres, A.W.; T. Mau-Lastovicka and R. Ruzaaiyan (1987). Total phenolics and high performance liquid chromatography of phenolic acids of avocado. Journal of Agriculture Food Chemistry 35: 921-925.
Visai, C. and M. Vanoli (1997). Volatile compound production during growth and ripening of Peaches and nectarines. Scientia Horticulture 70: 15-24.

Walker, R.; S. Sykes and J. Possingham (1990). Fruit crops with potential in Australia: the Mexican white sapote. Agric. Sci. 3(6): 32-34.

Werman, M.J. and I. Neeman (1987). Avocado oil production and chemical characteristics. JAOCS, 64(2): 229-232.

Yamaguchi, K.; O. Nishimura; H. Toda; S. Mihara and T. Shibamoto (1983). Chemical studies on tropical fruits. In: Instrumental Analysis of Foods. (eds.), Charalambous, G. and G. Inglett, Vol 2; 93-117, Academic, Orlando.

Yonemoto, Y.; H. Higuchi; K. Ishihata and E. Tomita (2000). Effect of artificial medium conditions on in vitro germination and storage conditions of white sapote (casimiroa edulis) pollen. Japanese J. of Tropical Agric. Japanese Society for Tropical Agic., Tokyo, Japan: 44(3): 171177.

Yonemoto, Y.; H. Higuchi and Y. Kitano (2002). Fruit ripening as affected by storage temperature in white sapote (Casimiroa edulis Llave and Lex) Japanese J. of Tropical Agric. Japanese Society for Tropical Agric., Tokyo, Japan 46(2): 82-87.

Yonemoto, Y.; K.Nomura; M. Ide; H. Inoue; M. Majikina and H. Okuda (2006). Index for harvesting time of white sapote (casimiroa edulis Llave and Lex.) cv. Cuccio. J. of Horticultural Sci. and Biotechnology, 81(1): 18-22. 